\title{
OPTIMIZATION, ISOLATION AND CHARACTERIZATION OF BIOACTIVE COMPOUNDS FROM STREPTOMYCES LAVENDULOCOLOR VHB-9
}

\author{
HIMA BINDU BSSN, RAJESH KUMAR MUNAGANTI, VIJAYALAKSHMI MUVVA*, KRISHNA NARAGANI, \\ MANI DEEPA INDUPALLI
}

Department of Botany and Microbiology, Acharya Nagarjuna University, Guntur - 522 510, Andhra Pradesh, India. Email: profmuvva@gmail.com

Received: 07 May 2018, Revised and Accepted: 07 May 2018

\section{ABSTRACT}

Objectives: Optimization, isolation, and characterization of bioactive compounds from Streptomyces lavendulocolor VHB-9 isolated from granite mines of Mudigonda village of Khammam district of Telangana state.

Methods: The potent strain was identified as S. lavendulocolor VHB-9 by polyphasic taxonomy. The influence of culture conditions on growth and bioactive compounds production was investigated. Purification of bioactive compounds was done using column chromatography. The structures of the compounds were elucidated on the basis of spectroscopic analysis including Fourier transform infrared, electron spray ionization mass spectrophotometry, ${ }_{1}^{1} \mathrm{H}$ nuclear magnetic resonance (NMR), and ${ }^{13} \mathrm{C}$ NMR. The antimicrobial activity of the compounds produced by the strain was tested against both Gram-positive and Gram-negative bacteria and fungi in terms of minimum inhibitory concentration.

Results: Isolation and identification of two compounds, namely $(2 R, 3 R)-2,3$-Butanediol (B1A), and nonadecanoic acid (B1B). Fraction B4 was isolated partially purified fraction and identified by the gas chromatography-mass spectrometry analysis. B1B compound exhibited the highest activity against Bacillus megaterium, Staphylococcus aureus, Bacillus subtilis, Pseudomonas aeruginosa, and Candida albicans when compared to B1A and B4 compounds.

Keywords: Granite mine, Streptomyces lavendulocolor, Optimization, Spectroscopy, Gas chromatography-mass spectrometry analysis, Biological assay. (C) 2018 The Authors. Published by Innovare Academic Sciences Pvt Ltd. This is an open access article under the CC BY license (http://creativecommons. org/licenses/by/4. 0/) DOI: http://dx.doi.org/10.22159/ajpcr.2018.v11i8.25345

\section{INTRODUCTION}

Natural products have been the largest contributors to drugs in the history of medicine. Microorganisms are attractive resources to synthesize structurally-diverse substances with various bioactivities that may be used as effective drugs or act as drug lead compounds that could be further modified and developed for higher efficacy [1]. Within the domain bacteria, actinomycetes showed unprecedented ability to produce potentially novel, clinically useful, secondary metabolites with anticancer, antioxidant, antiviral, and antibacterial compounds, the majority of these being derived from the members of the Streptomyces genus that include different classes of antibiotics including aminoglycosides, macrolides, and Beta-lactams [2].

Newer therapeutic agents such as daptomycin, linezolid, and streptogramin combination (quinupristin/dalfopristin) have entered the clinical area in the past few years to combat the multidrugresistant bacteria [3]. However, certain undesirable side effects and the spread of pathogens with this new antimicrobial drug resistance emphasize the need for the development of other newer antimicrobial agents with activity against Gram-positive bacteria, Gram-negative environmental, and enteric organisms currently threaten patients in hospitals and communities with multidrug resistance [4]. The end result of this phenomenon is that many strains of bacteria have become resistant, and in many cases multi-resistant to these therapeutic agents, thus rendering these drugs ineffective as treatments of choice for severe infections caused by these pathogens [5]. Rising numbers of antibiotic unresponsive infectious disease agents confront patients worldwide [6], and consensus has emerged that it is essential that novel antibiotic classes be developed as part of the strategy to control the emerging drug-resistant pathogens.
Filamentous soil bacteria belonging to the genus Streptomyces are widely recognized as industrially important microorganisms and versatile producers of new secondary metabolites from different biosynthetic pathways, originate from different ecological niches that could be used to hunt for novel bioactive compounds. The great importance given to Streptomyces is partly because these are among the most numerous and most versatile soil microorganisms, given their large metabolite production rate and their biotransformation processes, their capability of degrading lignocellulose and chitin, and their fundamental role in biological cycles of organic matter. Indeed, different Streptomyces species produce about $75 \%$ of commercially and medically useful antibiotics. They have provided more than half of the naturally occurring antibiotics discovered to date and continue to be screened for useful compounds [7]. In the course of screening for new antibiotics, several studies are oriented toward isolation of Streptomycetes from different habitats.

In the view of that the strain S. lavendulocolor VHB-9 was isolated from a granite mine of Mudigonda village of Khammam district of Telangana state, India. An attempt was made in the present study to optimize the cultural parameters required for best yields of bioactive metabolites, and chemical characterization of the compounds was also investigated.

\section{METHODS}

Chemicals

All solvents, reagents, and media supplements used in this study were of extra pure grade and procured from Merck (Mumbai, India).

\section{Strain isolation}

The strain, S. lavendulocolor VHB-9, was isolated on yeast extract-malt extract-dextrose (YMD) agar medium by soil dilution technique from 
a soil sample collected from granite mines of Mudigonda, Khammam District, Telangana state, India. The medium was composed of malt extract ( $1 \%)$, yeast extract $(0.4 \%)$, dextrose $(0.4 \%), \mathrm{CaCO}_{3}(0.2 \%)$, and agar $(2.0 \%)$, pH $7.0 \pm 0.2$. The strain was stored on YMD agar slants at $4^{\circ} \mathrm{C}$.

\section{Antimicrobial profile of bioactive metabolites produced by the} strain

The antimicrobial profile of the strain S. lavendulocolor VHB-9 was studied by cultivating the strain in YMD broth at $30^{\circ} \mathrm{C}$ for 8 days. The antimicrobial activity of bioactive metabolites against Staphylococcus aureus (MTCC 3160), Lactobacillus casei, Bacillus megaterium (NCIM 2187), Proteus vulgaris (ATCC 6380), Pseudomonas aeruginosa (ATCC 9027), Escherichia coli (ATCC 9027), Aspergillus niger, Fusarium solani, Fusarium oxysporum, and Candida albicans (MTCC 183) was determined by agar well diffusion assay, and inhibition zones against test microbes were determined [8]

\section{Media optimization}

Attempts were made to enhance the antimicrobial activity of $S$. lavendulocolor VHB-9 by optimizing the culture conditions such as $\mathrm{pH}$, temperature, carbon sources, nitrogen sources, and minerals. The bioactive metabolite production of the strain was determined after 4 days of incubation. Fermentation was carried out in 250-mL Erlenmeyer flasks with constant shaking at $180 \mathrm{rpm}$. The effect of initial $\mathrm{pH}$ on the bioactive metabolite production was determined by adjusting $\mathrm{pH}$ of the production medium from 4 to 10 . The optimal $\mathrm{pH}$ achieved at this step was fixed for further study [9]. Similarly, the optimum temperature for antimicrobial metabolite production was determined by incubating the strain at temperatures ranging from 20 to $40^{\circ} \mathrm{C}$, while maintaining all other conditions at optimum levels [10]. The effect of carbon sources on bioactive metabolite production was determined by supplementing the production medium (YMD) with different carbon sources such as maltose, sucrose, mannitol, lactose, starch, cellulose, galactose, sorbitol, and fructose each at a concentration of $0.4 \%$ $(\mathrm{w} / \mathrm{v})$ replacing dextrose by keeping the other ingredients constant [11]. Influence of varying concentrations of the best carbon source $(0.5-4 \% \mathrm{w} / \mathrm{v})$ on bioactive metabolite production was also investigated.

Similarly, the influence of various nitrogen sources such as sodium nitrate, ammonium oxalate, ammonium sulfate, peptone, tryptophan, L-proline, tyrosine, urea, and yeast extract was studied by adding nitrogen source $(0.4 \%)$ to the medium with an optimized carbon source. Further, the optimal levels of the suitable nitrogen source $(0.1-1.5 \% \mathrm{w} / \mathrm{v})$ for good yields of bioactive metabolites were also recorded [12]. To evaluate the effect of mineral salts, the optimized medium containing the superior carbon and nitrogen source was supplemented separately with mineral supplements such as $\mathrm{KH}_{2} \mathrm{PO}_{4}, \mathrm{~K}_{2} \mathrm{HPO}_{4}, \mathrm{NaCl}, \mathrm{KCl}, \mathrm{MgSO}_{4} .7 \mathrm{H}_{2} \mathrm{O}, \mathrm{FeSO}_{4} .7 \mathrm{H}_{2} \mathrm{O}$, and $\mathrm{MnCl}_{2}$ at a concentration of $0.05 \%(\mathrm{w} / \mathrm{v})$ [13].

\section{Extraction of the metabolite and antimicrobial activity assay}

The strain S. lavendulocolor VHB-9 grown under optimized cultural conditions for 4 days was extracted with ethyl acetate, and concentrated in a rotary evaporator to obtain a crude extract. The antimicrobial metabolites produced were tested by agar well diffusion assay against the following test microorganisms:

\section{Bacteria}

Overnight grown cultures of S. aureus (MTCC 3160), Bacillus subtilis (ATCC 6633), B. megaterium (NCIM 2187), Shigella flexneri (MTCC 1457), L. casei (MTCC 1423), Lactobacillus acidophilus (MTCC 495), Proteus vulgaris (MTCC 7299), P. aeruginosa (ATCC 9027), E. coli (ATCC 35218), Vibrio cholerae, and Streptococcus mutans (MTCC 497) were used.

Fungi

C. albicans (ATCC 10231), A. niger, Aspergillus flavus, F. solani, F. oxysporum (MTCC 3075), Penicillium citrinum, and Alternaria sp. were used as test fungi for testing antifungal activity.
Extraction, purification, and characterization of antimicrobial compounds

\section{Fermentation}

A seed culture was prepared by culturing S. lavendulocolor VHB-9 in YMD broth and incubated on a rotary shaker $(180 \mathrm{rpm})$ at $30^{\circ} \mathrm{C}$ for $48 \mathrm{~h}$. The seed culture was then transferred to fermentation broth containing malt extract - $1 \%$, lactose $-0.5 \%$, peptone $-0.5 \%$, and $\mathrm{K}_{2} \mathrm{HPO}_{4}-0.05 \%$ with $\mathrm{pH}$ adjusted to 7 and incubated on rotary shaker $(180 \mathrm{rpm})$ at $30^{\circ} \mathrm{C}$ for $120 \mathrm{~h}$. The bioactive compounds from the fermented broth were harvested by filtration of biomass through Whatman Filter Paper No. 42 (Merck, Mumbai, India). The culture filtrate $(30 \mathrm{~L})$ was extracted twice with an equal volume of ethyl acetate, pooled and the organic layer was concentrated in a Rotavac. The deep brown semi-solid compound ( $3.0 \mathrm{~g}$ ) obtained was applied to a silica gel G column $(25 \mathrm{~cm} \times 5 \mathrm{~cm}$, Silica gel, Merck, Mumbai, India).

The separation of the crude extract was carried out through gradient elution system of hexane: ethyl acetate. The eluent was run over the column, and small volumes of eluent collected in test tubes were analyzed through thin-layer chromatography (TLC) using silica gel plates (Silica gel, Merck, Mumbai, India) with hexane: ethyl acetate solvent system [14]. Compounds with identical retention factors $\left(R_{\mathrm{f}}\right)$ were combined and assayed for antimicrobial activity against Grampositive (B. megaterium), Gram-negative (E. coli) bacteria, and yeast (C. albicans) by using agar well diffusion assay [15].

Among the different fractions, two fractions B1 (polar) and B4 (nonpolar) were collected at gradient solvent system of Hexane: ethyl acetate $(70-30 \mathrm{v} / \mathrm{v}$ and $90-10 \mathrm{v} / \mathrm{v})$. The B1 fraction was rechromatographed $(22 \times 2.5 \mathrm{~cm}$, Silica gel 100; Merck) to get two pure compounds $((2 R, 3 R)-2,3$-Butanediol (B1A), and nonadecanoic acid [B1B]). The structures of these active fractions were analyzed on the basis of Fourier transform infrared (FTIR); model: Thermo Nicolet Nexus 670 spectrophotometer with $\mathrm{NaCl}$ optics and electron ionization mass/electron spray ionization mass spectrophotometry (EIMS/ ESIMS); model: Micromass VG - 7070H, 70eV spectrophotometer and nuclear magnetic resonance (NMR) $\left({ }^{1} \mathrm{H}\right.$ NMR and ${ }^{13} \mathrm{C}$ NMR) model: Varian Gemini 200 and samples were made in $\mathrm{CDCl}_{3}$ with trimethyl saline as standard.

Fractions B4 obtained as a mixture of compounds analyzed on Agilent gas chromatography-mass spectroscopy (GC-MS) system. The fused silica HP-5 capillary column $(30 \mathrm{~m} \times 0.25 \mathrm{~mm}$, ID, film thickness of $0.25 \mu \mathrm{m}$ ) was directly coupled to the MS. The carrier gas was helium with a flow rate of $1.2 \mathrm{ml} / \mathrm{min}$. Oven temperature was programmed $\left(50^{\circ} \mathrm{C} / \mathrm{min}\right.$ ), then $50-280^{\circ} \mathrm{C}$ (at rate of $5^{\circ} \mathrm{C} / \mathrm{min}$ ) and subsequently held isothermally for $20 \mathrm{~min}$. The temperature of the injector port was maintained at $250^{\circ} \mathrm{C}$ and that of the detector at $280^{\circ} \mathrm{C}$ [16]. The peaks of components in gas chromatography were subjected to mass spectral analysis. The spectra were analyzed from the available library data NIST MS search (ver. 2.0) (Included with NIST'02 mass spectral library, Agilent p/n G 1033 A).

\section{Biological assays}

\section{Minimum inhibitory concentration (MIC)}

The MIC of antimicrobial metabolites produced by the strain was determined against Gram-positive as well as Gram-negative bacteria and fungi using agar plate well-diffusion assay [15]. Nutrient agar and Czapek-Dox agar media were used for culturing bacteria and fungi, respectively. Sterilized agar medium seeded with the test bacterial suspension was transferred to Petri plates under aseptic conditions. After the solidification of agar medium, wells about $6 \mathrm{~mm}$ diameter were cut into it with a sterilized cork borer. In case of the antifungal assay, test fungus $\left(10^{5}\right.$ spores $\left./ \mathrm{ml}\right)$ was plated on to the solidified agar medium. Metabolites dissolved in dimethyl sulfoxide (DMSO) at concentrations ranging from 0 to $1000 \mu \mathrm{g} / \mathrm{ml}$ were added to the wells. 
After inoculation the plates were incubated at $30^{\circ} \mathrm{C}$ and examined after 24-48 h of incubation for bacteria and 48-72 h for yeast and filamentous fungi. The experiment was carried out in triplicates, and the solvent (DMSO) alone was kept as a negative control. Tetracycline and Carbendazim were employed as positive controls for bacteria and fungi, respectively. The lowest concentration of the bioactive compound exhibiting antimicrobial activity against the test microbes was taken as MIC of the compound

The MICs of the bioactive compounds (B1A, B1B, and B4) produced by the strain were determined against several opportunistic pathogenic bacteria and fungi.

\section{Test organisms employed}

The cultures of S. aureus (MTCC 3160), B. megaterium (NCIM 2187), B. subtilis (ATCC 6633), Serratia marcesens (MTCC 1457), Xanthomonas campestris (MTCC 2286), P. vulgaris (MTCC 7299), P. aeruginosa (ATCC 9027), E. coli (ATCC 35218), Enterococcus faecalis (MTCC 439), S. mutans (MTCC 497), L. casei (MTCC 1423), and L. acidophilus (MTCC 495) were employed for antibacterial assay. C. albicans (ATCC 10231), A. niger (ATCC 1015), A. flavus (ATCC 9643), F. solani (MTCC 4634), F. oxysporum (MTCC 3075), and Penicillium citrinum (MTCC 6489) were used for testing antifungal activity.

\section{Statistical analysis}

The results of bioactive metabolite production by $S$. lavendulocolor VHB-9 under different cultural conditions were statistically analyzed with one-way analysis of variance (ANOVA).

\section{RESULTS AND DISCUSSION}

Antimicrobial profile of bioactive metabolites produced by the strain

The growth pattern of $S$. lavendulocolor VHB-9 cultured in YMD broth was reported on our earlier publication [17]. The strain entered log phase after $24 \mathrm{~h}$ of incubation and exhibited exponential growth up to $96 \mathrm{~h}$ followed by stationary phase extended up to $120 \mathrm{~h}$. The crude extract obtained from a 4-day-old culture exhibited high antimicrobial activity against the test microorganisms (Fig. 1). A previous report demonstrated high antimicrobial activity of crude extracts of a 4-dayold culture of Arthrobacter kerguelensis VL-RK_09 [18]. The metabolites collected from 4-day-old culture of Streptomyces griseus exhibited good antifungal activity [19]. Similarly, the extracts of 4-day-old cultures of Streptomyces psammoticus [20], Streptomyces tendae TKVL_ 333 [21], and Nocardia levis MK-VL_113 [22] were active against test bacteria and fungi.

Crude extracts of 5-day-old cultures of Streptomyces purpeofuscus [23] and Streptomyces albidoflavus [24] were active against Gram-positive as well as Gram-negative bacteria and fungi. Secondary metabolites extracted from 5-day-old cultures of Streptomyces sp. CDRIL-312 [25] and Streptomyces spp. [12] exhibited good antifungal activity. 5-day-old culture of Streptomyces clavuligerus was reported to produce a good yield of clavulanic acid [26] whereas 6-day-old culture of Streptomyces sp. 201 exhibited good antimicrobial activity [27].

\section{Impact of $\mathrm{pH}$ and temperature on antimicrobial activity}

The influence of initial $\mathrm{pH}$ on growth and bioactive metabolite production of the strain was determined by adjusting the $\mathrm{pH}$ of YMD broth from 4 to10. Maximum growth and antimicrobial metabolite production by the strain were found at $\mathrm{pH} 7$ through the strain was able to grow over a wide range of $\mathrm{pH}$ (Fig. 2). The optimum $\mathrm{pH}$ for antibiotic production by several actinomycetes was reported to be 7 for Streptomyces hygroscopicus D1.5 [28], Streptomyces torulosus KH- 4 [29], Streptomyces sp. VITSVK 9[30], Streptomyces cellulosae VJDS-1 [31], Rhodococcus erythropolis VLK-12 [32], and A. kerguelensis VL-RK_09 [18].

The yield of bioactive metabolites of the strain was also recorded when grown at temperatures of $20-40^{\circ} \mathrm{C}$, and the optimum was recorded at $30^{\circ} \mathrm{C}$ (Fig. 3). With the rise of incubation temperature from 20 to $30^{\circ} \mathrm{C}$, there was an increase in bioactive metabolite production. However, further, increase in temperature (above $30^{\circ} \mathrm{C}$ ) resulted in the declined production of bioactive metabolites. These results are in agreement with the earlier reports for Streptomyces [29].

\section{Effect of carbon and nitrogen sources on antimicrobial activity}

The effect of various carbon sources on antimicrobial metabolite production was tested by supplementing the YMD broth with several carbon sources at a concentration of $0.4 \%$ (replacing the dextrose) while making all other ingredients of the media same and incubated for $96 \mathrm{~h}$ at $30^{\circ} \mathrm{C}$. The effects of carbon sources on the production of bioactive metabolites by $S$. lavendulocolor VHB-9 are presented in Fig. 4. Among the carbon sources tested, significant production of bioactive metabolites was obtained with lactose followed by sucrose. These results are supported by the reports of $S$. hygroscopicus strains AK-111-81 and CH-7, which utilized lactose as a carbon source for high antimicrobial metabolite production [33,34]. Since lactose supported a high yield of bioactive metabolites, different concentrations of lactose $(0.5-4 \%)$ were tested to determine the optimal concentration. Lactose at a concentration of $0.5 \%$ supported the highest yield of bioactive metabolites (Fig. 5).

The effect of various nitrogen sources on antimicrobial metabolite production was tested by supplementing the YMD broth with several nitrogen sources at a concentration of $0.4 \%$ to the YMD broth (replacing yeast extract). Peptone was found to be good as compared to other organic and inorganic nitrogen sources tested (Fig. 6). These results are comparable with $S$. rochei G164 [35] and S. scabies PK-A41 [36]. Since peptone enhanced the antimicrobial metabolite production by the strain, the effects of different concentrations of peptone were tested

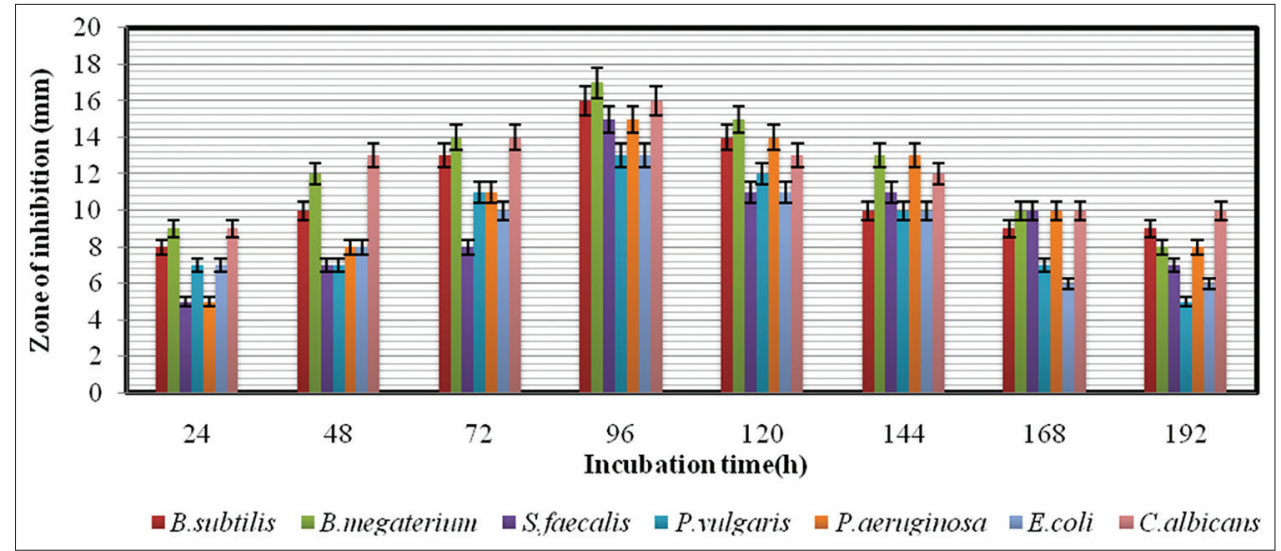

Fig. 1: Time course of bioactive metabolite production by Streptomyces lavendulocolor VHB-9. The data were statistically analyzed and found to be significant at a $5 \%$ level 


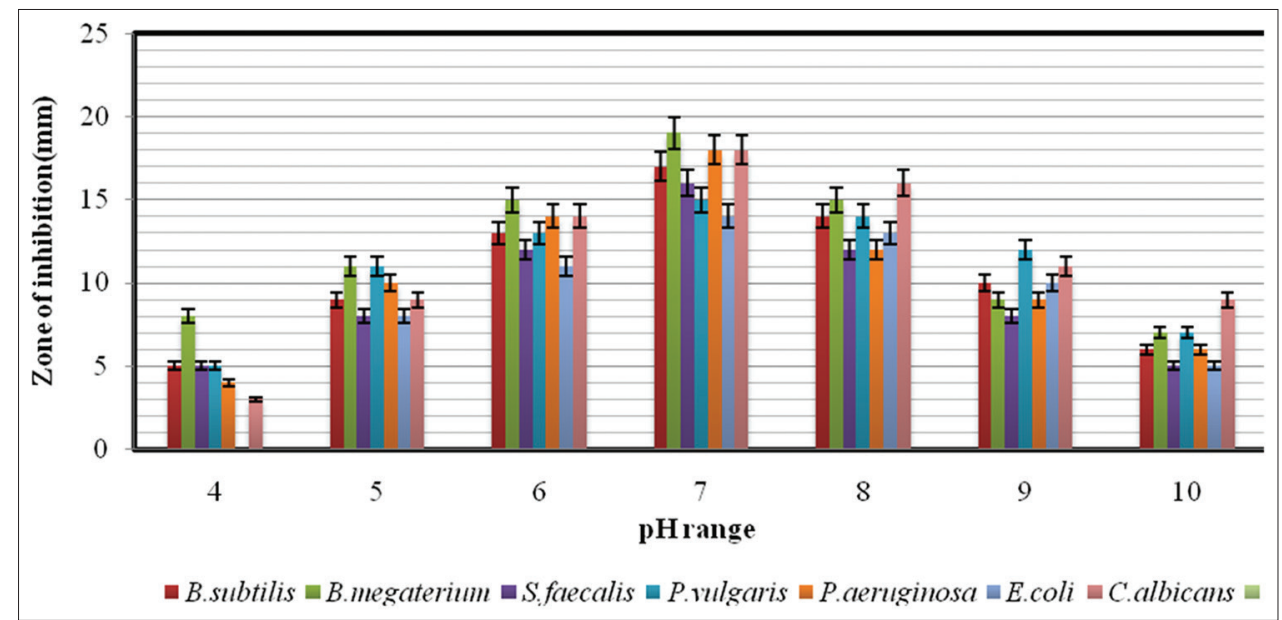

Fig. 2: The effect of $\mathrm{pH}$ on the bioactive metabolite production by Streptomyces lavendulocolor VHB-9. The data were statistically analyzed and found to be significant at a $5 \%$ level

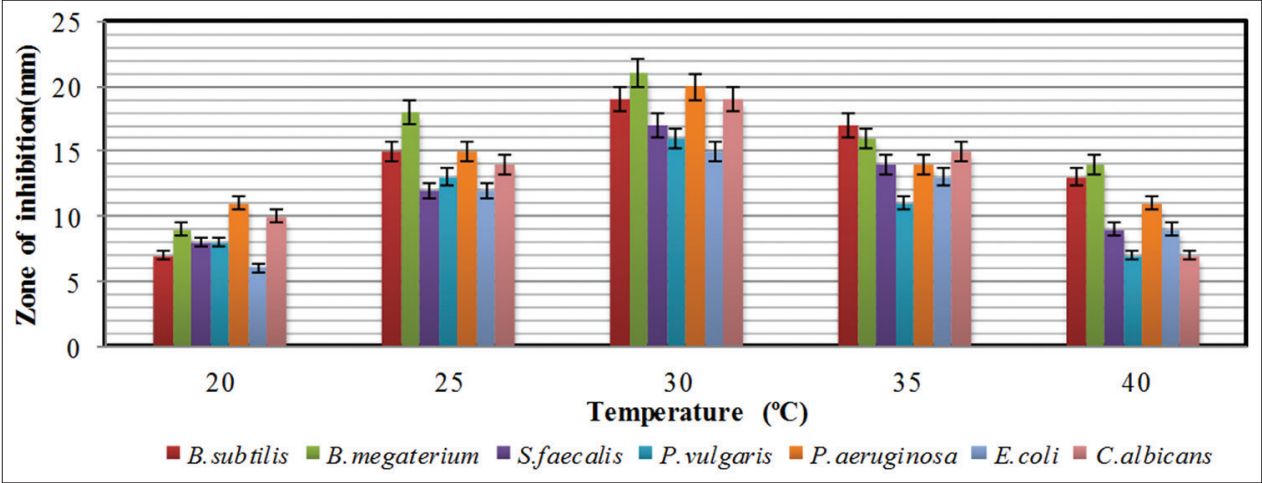

Fig. 3: The effect of temperature on the bioactive metabolite production by Streptomyces Iavendulocolor VHB-9. The data were statistically analyzed and found to be significant at a $5 \%$ level

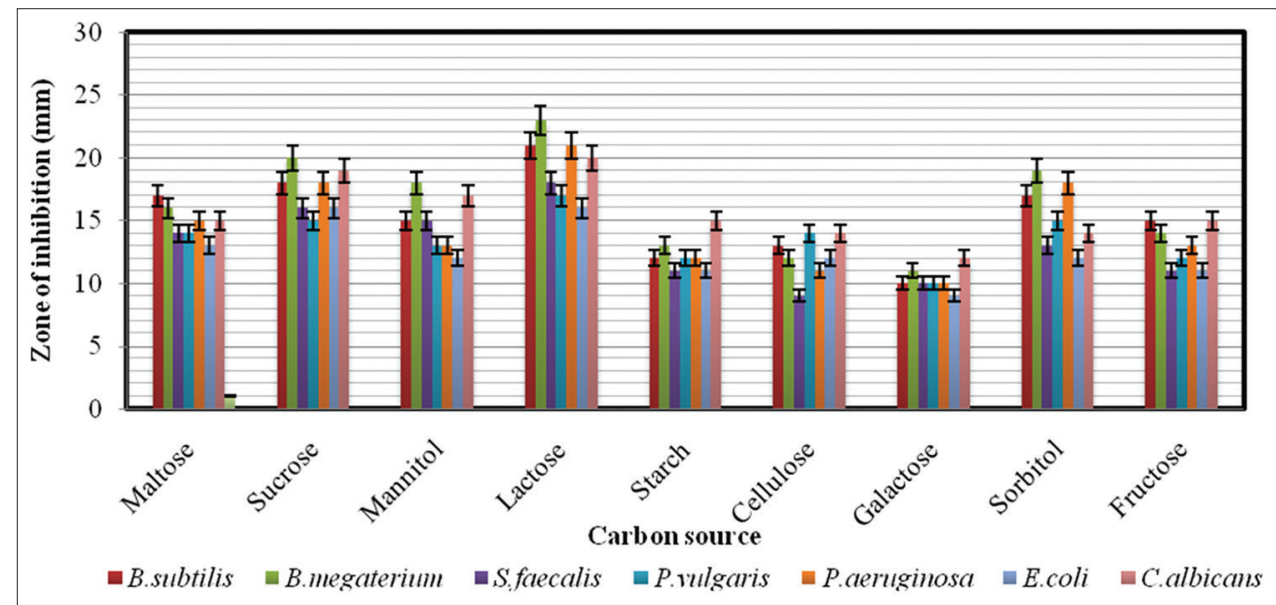

Fig. 4: The effect of carbon sources supplemented in the modified yeast extract-malt extract-dextrose broth on bioactive. Metabolite production by Streptomyces lavendulocolor VHB-9. The data were statistically analyzed and found to be significant at a $5 \%$ level

(Fig. 7). An enhanced level of bioactive metabolite production was found with peptone at a concentration of $0.5 \%$. L-asparagine $(0.09 \%)$ was reported as the suitable nitrogen source for optimum production of bioactive metabolites by Streptomyces sp. [27] S. rubrolavendulae ICN3 was reported to exhibit best anti-MRSA and cytotoxic activity when glucose and sodium nitrate were amended to the medium as carbon and nitrogen sources, respectively [37]
The effect of mineral salts on antimicrobial activity

The effect of mineral salts on secondary metabolite production by the strain VHB-9 is shown in Fig. 8. Among the mineral salts tested, $\mathrm{K}_{2} \mathrm{HPO}_{4}$ supported the highest antimicrobial activity. Similar results were reported for S. albidoflavus [24] Ripa et al. (2009) and Usha et al. (2011) reported that $\mathrm{K}_{2} \mathrm{HPO}_{4}$ supported antibiotic production by Streptomyces sp. RUPA-08PR and Pseudonocardia spp. [38,39]. 


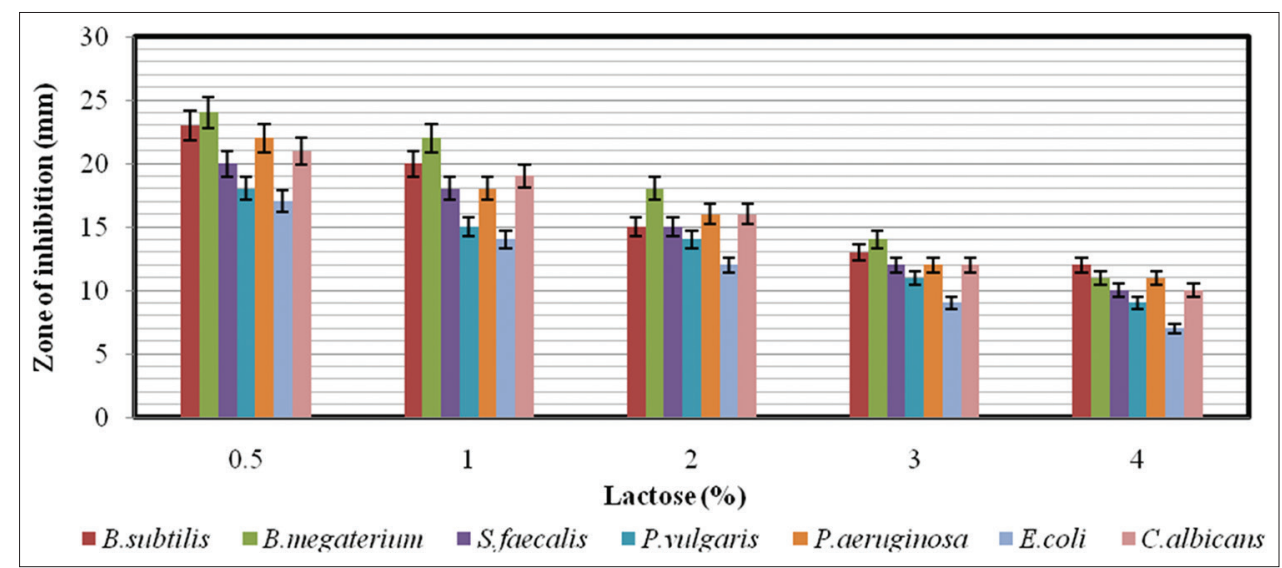

Fig. 5: The effect of different concentrations of lactose as carbon source on antimicrobial activity of Streptomyces lavendulocolor VHB-9. The data were statistically analyzed and found to besignificant at a $5 \%$ level

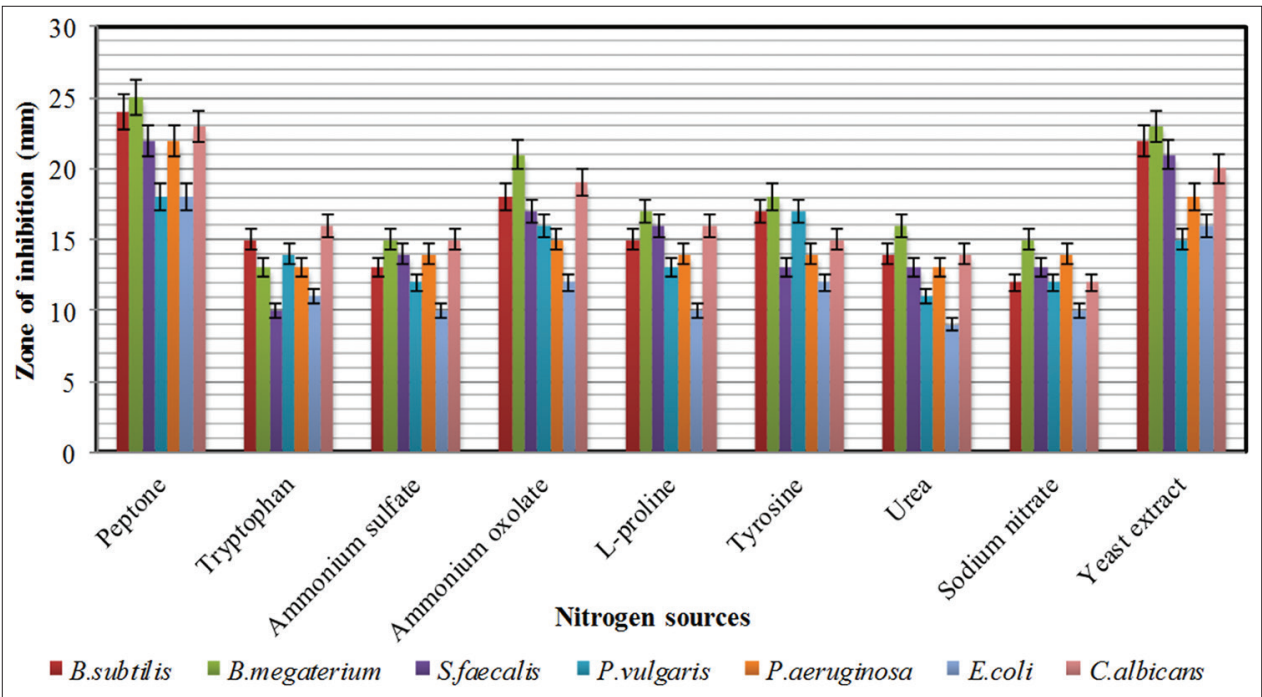

Fig. 6: The effect of various nitrogen sources supplemented in the modified yeast extract-malt extract-dextrose broth on the antimicrobial activity of Streptomyces lavendulocolor VHB-9. The data were statistically analyzed and found to be significant at a 5\% level

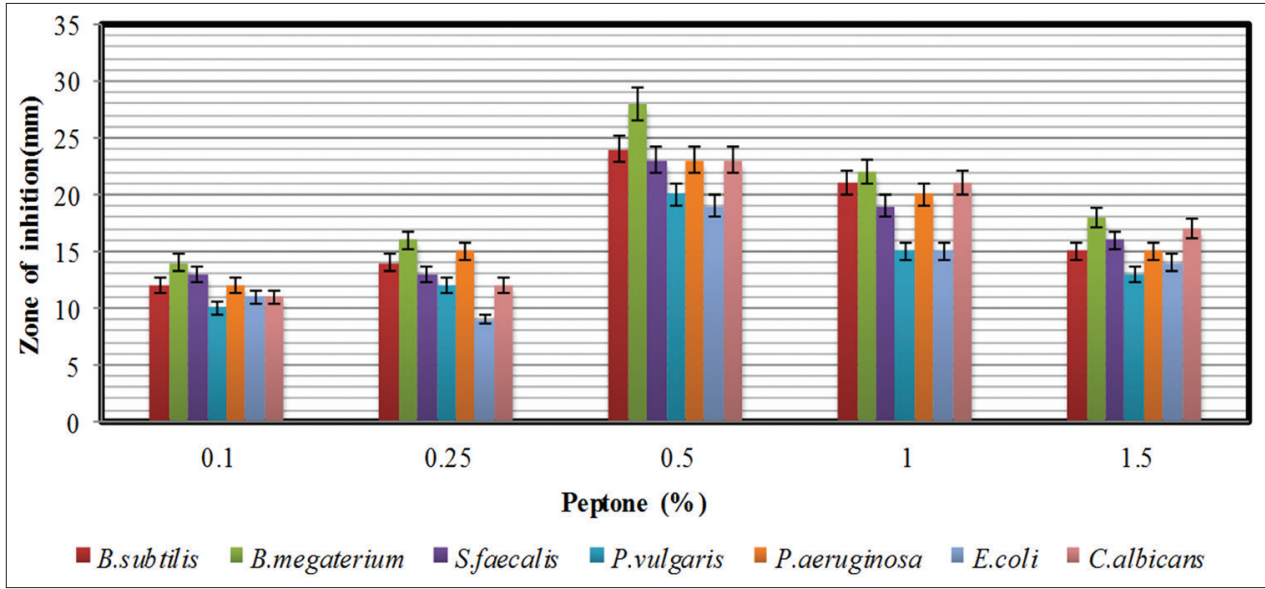

Fig. 7: The effect of different concentrations of peptone as nitrogen source on the antimicrobial activity of Streptomyces lavendulocolor VHB-9. The data were statistically analyzed and found to be significant at a $5 \%$ level

The strain VHB-9 is grown in the optimized fermentation medium containing lactose $(0.5 \%)$, peptone $(0.5 \%), \mathrm{K}_{2} \mathrm{HPO}_{4}(0.05 \%)$, and $\mathrm{CaCO}_{3}(0.2 \%)$ with $\mathrm{pH}$ adjusted to 7.0 and incubated at $30^{\circ} \mathrm{C}$. After $96 \mathrm{~h}$ of incubation, the fermentation broth extracted with ethyl acetate exhibited good antimicrobial activity against Gram-positive as well as Gram-negative bacteria and fungi (Table 1). Among the bacteria tested, $B$. megaterium was highly sensitive to the metabolites followed by B. subtilis, S. aureus, P. aeruginosa, S. flexneri, L. Casei, and L. acidophilus. 


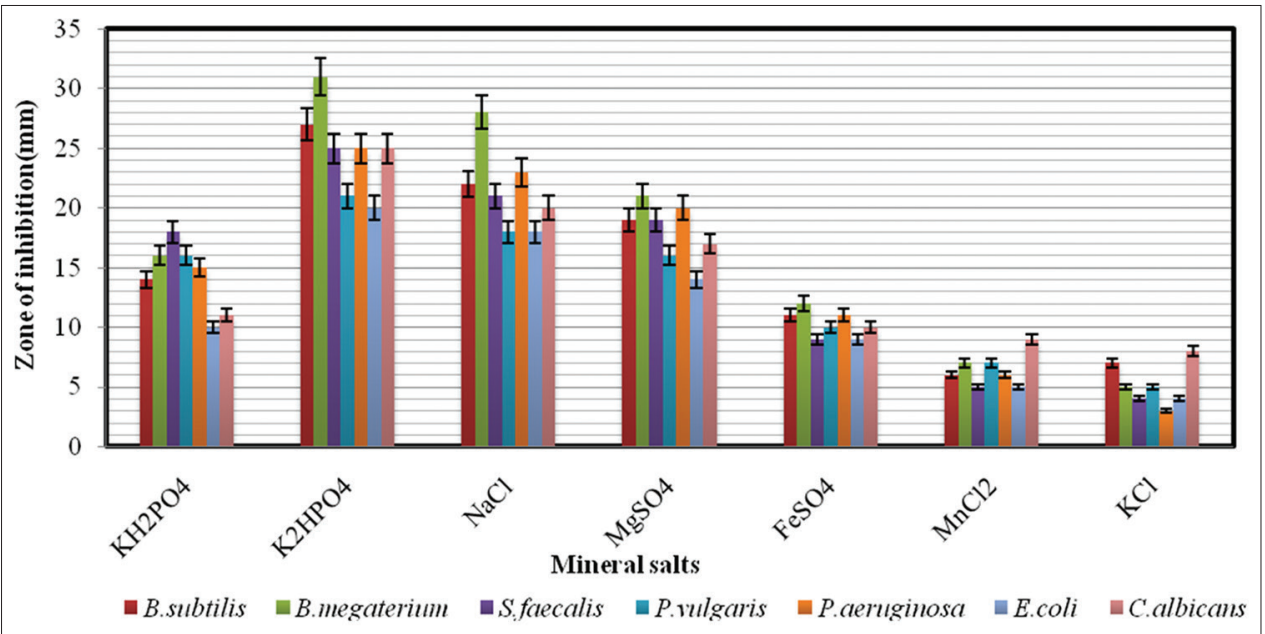

Fig. 8: The effect of mineral salts on the antimicrobial activity of Streptomyces lavendulocolor

Table: 1 Antimicrobial activity of $S$. lavendulocolor VHB-9 under optimized culturing conditions

\begin{tabular}{lll}
\hline S. No. & Test organisms & Zone of inhibition (mm) \\
\hline 1 & Staphylococcus aureus & 27 \\
2 & Bacillus megaterium & 31 \\
3 & Shigella flexneri & 25 \\
4 & Bacillus subtilis & 28 \\
5 & Proteus vulgaris & 21 \\
6 & Pseudomonas aeruginosa & 26 \\
7 & Escherichia coli & 21 \\
8 & Streptococcus mutans & 22 \\
9 & Vibrio cholera & 21 \\
10 & Lactobacillus casei & 25 \\
11 & Lactobacillus acidophilus & 23 \\
& Fungi & \\
12 & Candida albicans & 25 \\
13 & Aspergillus niger & 21 \\
14 & Aspergillus flavis & 19 \\
15 & Fusarium solani & 18 \\
16 & Fusarium oxysporum & 17 \\
17 & Penicillium citrinum & 18 \\
18 & Alternaria sp. & 17 \\
\hline
\end{tabular}

Among the fungi tested, $C$. albicans exhibited high sensitivity followed by A. niger, A. flavus, F. solani, Penicillium citrinum, F. oxysporum, and Alternaria sp.

Isolation, purification, and structural elucidation of active metabolites

The culture filtrates $(30 \mathrm{~L})$ collected after $96 \mathrm{~h}$ of incubation were extracted twice with ethyl acetate and concentrated to dryness in a Rotavac. The crude dark brown residue $(3.0 \mathrm{~g})$ thus obtained was subjected to silica gel column chromatography. The crude extract was applied to a silica gel G column $(25 \mathrm{~cm} \times 5 \mathrm{~cm}$, Silica gel, Merck, Mumbai, India) for the isolation and purification of bioactive compounds.

Among the fractions collected, two fractions (B1 and B4) collected at gradient solvent system of Hexane: ethyl acetate $(70-30 \mathrm{v} / \mathrm{v}$ and 90-10 v/v) were analyzed. The B1 fraction was re-chromatographed $(22 \mathrm{~cm} \times 2.5 \mathrm{~cm}$, Silica gel 100; Merck) to get two pure compounds, B1A $(25 \mathrm{mg})$ and B1B $(20 \mathrm{mg})$. The fraction B4, obtained as a mixture was analyzed by GC-MS system.

B1A eluted with 30\% ethyl acetate appeared as light brown liquid soluble in $\mathrm{CHCl}_{3}, \mathrm{MeOH}, \mathrm{DCM}$, and DMSO. The IR absorption maxima Vmax at $3437 / \mathrm{cm}$ suggested the presence of functional $\mathrm{OH}$ group. In ESIMS, the compound showed molecular ions at $m / z=108$ inferring

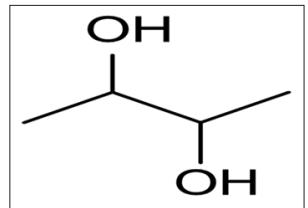

Fig. 9: Molecular structure of $(2 R, 3 R)-2,3$-butanediol

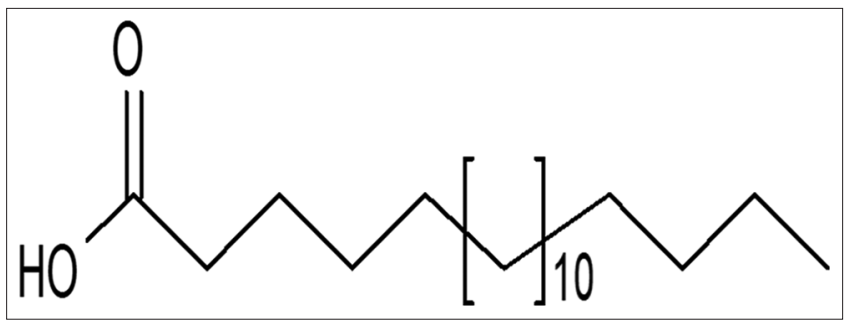

Fig. 10: Molecular structure of nonadecanoic acid

the molecular weight of $\mathrm{C}_{4} \mathrm{H}_{28} \mathrm{O}_{2}[\mathrm{M}+\mathrm{NH} 3]+$. The proton NMR of the compound displayed proton signals at $\delta 3.81(2 \mathrm{H}, \mathrm{Qd}, J=6.04 \mathrm{~Hz})$ due to methylene protons bearing hydroxyl group, two exchangeable protons at $\delta 1.93$ (br s, $\mathrm{OH}$ ), at $\delta 1.67$ (br s, $\mathrm{OH}$ ) and two methyl groups at $\delta 1.15(6 \mathrm{H}, \mathrm{d}, J=6.04 \mathrm{~Hz}){ }^{13} \mathrm{C}$ NMR depicted peaks at $\delta 70.81(2 \mathrm{C})$ and $\delta 16.90(2 \mathrm{C}) .(\alpha) \mathrm{D} 25=-12.5\left(\mathrm{c}=1, \mathrm{CHCl}_{3}\right)$. Based on the spectral data and optical rotation, B1A was identified as B1A Fig. 9). This is the first report of this compound from S. lavendulocolor VHB-9. The second fraction B1B in pure form appeared as brown liquid soluble in $\mathrm{CHCl}_{3}, \mathrm{MeOH}, \mathrm{DCM}$, and DMSO. The IR absorption maxima Vmax at $1708 / \mathrm{cm}$ suggested the presence of the carboxylic group. In ESIMS, the compound showed molecular ions at $m / z=298$ inferring the molecular weight of $\mathrm{C}_{19} \mathrm{H}_{38} \mathrm{O}_{2}[\mathrm{M}+1]+$. The proton NMR of the compound displayed signals at $\delta 1.65-1.55(30 \mathrm{H}, \mathrm{m}), 1.25-1.99(\mathrm{~m}, 2 \mathrm{H})$ for aliphatic methylene protons, at $\delta 2.35(\mathrm{t}, 2 \mathrm{H}, J=7.2 \mathrm{~Hz})$ for alpha methylene protons, at $\delta 1.25-1.99(\mathrm{~m}, 2 \mathrm{H})$ for methylene protons, and at $\delta 0.82$ $(\mathrm{t}, 3 \mathrm{H}, J=6.1 \mathrm{~Hz}$ ) for methyl protons. 13C NMR depicted peak at $\delta 180.8$ for the carboxylic group. Based on spectral data, the B1B was identified as nonadecanoic acid (B1B) (Fig. 10). This is the first report of this compound from the strain VHB-9.

The active nonpolar fraction B4 appeared as light brown was soluble in $\mathrm{CHCl}_{3}, \mathrm{MeOH}, \mathrm{DCM}$, and DMSO. The proton NMR of the compound revealed the presence of a mixture of compounds. The components of partially purified fourth fraction (B4) were analyzed on Agilent GCMS system. The peaks of components in gas chromatography were subjected to mass spectral analysis. The spectra were analyzed from the 


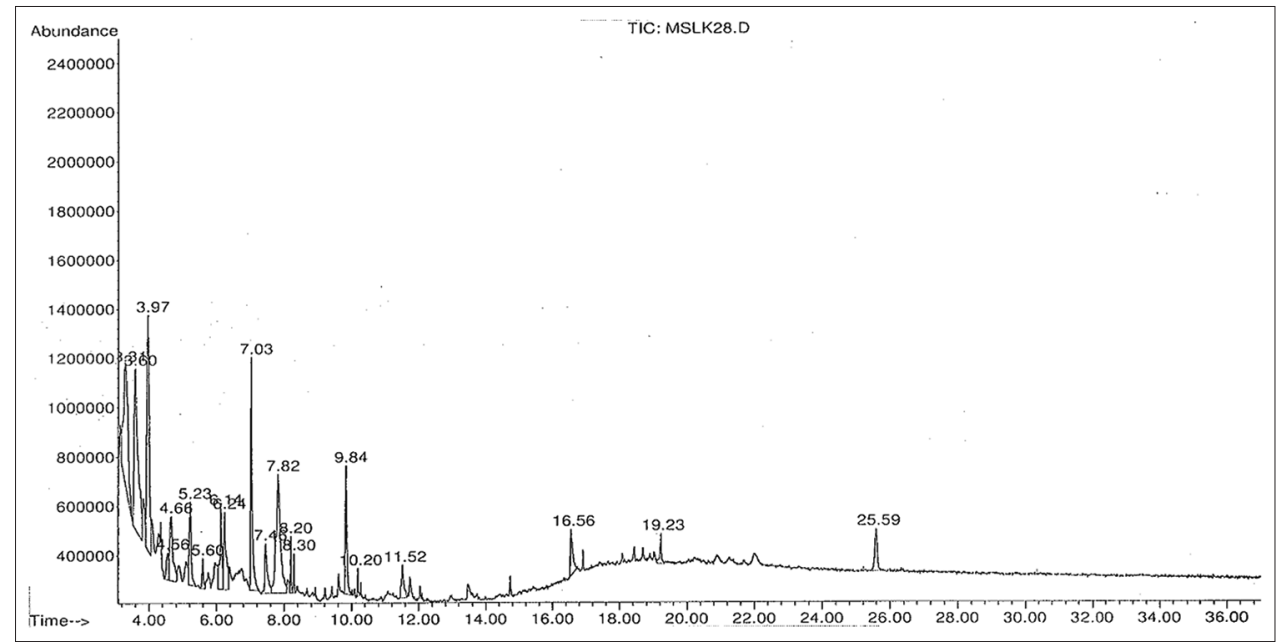

Fig. 11: Gas chromatographic spectrum of fraction B4 produced by Streptomyces lavendulocolor VHB-9

Table 2. List of compounds obtained from GC-MS analysis of fraction B4 produced by S. lavendulocolor VHB-9

\begin{tabular}{|c|c|c|c|c|}
\hline Peak No. & Compound name & Area & Retention time & Percent match \\
\hline 1 & 2-Ethoxy pentane & 13.05 & 3.30 & 38 \\
\hline 2 & Methoxy acetic acid & 14.19 & 3.60 & 43 \\
\hline 3 & Pentanoic acid & 13.60 & 3.97 & 52 \\
\hline 4 & Propanoic acid & 1.47 & 4.56 & 25 \\
\hline 5 & Benzene acetic acid & 4.57 & 4.66 & 25 \\
\hline 6 & Phenol, 2,4-bis-(1,1-dimethylethyl) & 3.97 & 5.22 & 96 \\
\hline 7 & 2,2-Diisopropyl1-1,3Dioxolane & 1.02 & 5.60 & 35 \\
\hline 9 & Hexadecene & 4.50 & 6.24 & 90 \\
\hline 10 & 4-Ethynyl-4-vinyl-1,6-heptadecene & 9.10 & 7.03 & 25 \\
\hline 11 & 6-Methylquinoline 1-oxide & 3.11 & 7.45 & 38 \\
\hline 12 & 2-Phenylpent-4-enol & 12.44 & 7.83 & 12 \\
\hline 13 & 5-Octadecene & 1.25 & 8.20 & 99 \\
\hline 14 & Octadecane & 0.83 & 8.30 & 93 \\
\hline 15 & n-Hexadecanoic acid & 4.43 & 9.84 & 98 \\
\hline 16 & 1-Tricosanol & 0.52 & 10.20 & 91 \\
\hline 18 & 13-Docsenamide & 2.47 & 16.56 & 93 \\
\hline 19 & Stigmastan-3,5-diene & 1.26 & 19.23 & 91 \\
\hline 20 & No match found & 2.36 & 25.59 & - \\
\hline
\end{tabular}

GC-MS: Gas chromatography-mass spectroscopy, S. lavendulocolor: Streptomyces lavendulocolor

Table 3: MIC values of the bioactive compounds produced by

$$
\text { S. lavendulocolor VHB-9 }
$$

\begin{tabular}{|c|c|c|c|c|}
\hline \multirow[t]{2}{*}{ Test organism B1A } & \multicolumn{4}{|c|}{$\operatorname{MIC}(\mu \mathrm{g} / \mathrm{ml})$} \\
\hline & \multirow[t]{2}{*}{ B1B } & \multicolumn{2}{|c|}{ B4 (PPF†) } & \multirow{2}{*}{$\begin{array}{l}\text { Positive } \\
\text { control }^{\#}\end{array}$} \\
\hline \multicolumn{3}{|l|}{ Bacteria } & & \\
\hline Bacillus megaterium & 65 & 40 & 75 & 30 \\
\hline Bacillus subtilis & 75 & 55 & 80 & 40 \\
\hline Serratia marcescens & 90 & 60 & 100 & 25 \\
\hline Xanthomonas campestris & 75 & 65 & 85 & 40 \\
\hline Proteus vulgaris & 100 & 80 & 100 & 50 \\
\hline Pseudomonas aeruginosa & 70 & 55 & 75 & 40 \\
\hline Escherichia coli & 90 & 60 & 95 & 25 \\
\hline Enterococcus faecalis & 95 & 75 & 100 & 25 \\
\hline Streptococcus mutans & 75 & 55 & 90 & 30 \\
\hline Lactobacillus casei & 85 & 55 & 100 & 25 \\
\hline Lactobacillus acidophilus & 80 & 55 & 95 & 25 \\
\hline Staphylococcus aureus & 65 & 50 & 80 & 25 \\
\hline \multicolumn{5}{|l|}{ Yeast } \\
\hline Candida albicans & 85 & 55 & 100 & 50 \\
\hline \multicolumn{5}{|l|}{ Fungi } \\
\hline Aspergillus niger & 90 & 55 & 125 & 5 \\
\hline Aspergillus flavus & 80 & 70 & 100 & 10 \\
\hline
\end{tabular}

Table 3: (Continued)

\begin{tabular}{lllll}
\hline Test organism B1A & \multicolumn{4}{l}{ MIC $(\mu \mathrm{g} / \mathrm{ml})$} \\
\cline { 2 - 5 } & B1B & B4 $(\mathbf{P P F} \dagger)$ & $\begin{array}{l}\text { Positive } \\
\text { control }^{\#}\end{array}$ \\
\hline Fusarium oxysporum & 90 & 75 & 100 & 10 \\
Fusarium solani & 90 & 65 & 125 & 10 \\
Penicillium citrinum & 100 & 75 & 125 & 10 \\
\hline
\end{tabular}

*MIC: Minimum inhibitory concentration, "Positive control: Tetracycline against bacteria, Griseofulvin against yeast and Carbendazim against fungi. B1A: (2R, 3R)-2, 3-Butanediol, B1B: Nonadecanoic acid, B4: PPF, PPF: Public provident fund, S. lavendulocolor: Streptomyces lavendulocolor

available library data NIST MS search (ver. 2.0) (Included with NIST'02 mass spectral library, Agilent p/n G 1033 A).

Compounds present in partially purified fraction were tentatively identified. The GC analysis revealed the presence of 20 compounds (Fig. 11). The list of compounds with their retention times is listed in Table 2.

Biological assay

MICs of compounds B1A, B1B, and B4 obtained from the strain against different microorganisms including bacteria and fungi in terms of 
MIC are shown in Table 3. B1B is more effective than B1A and B4. B. megaterium is highly sensitive to the compounds followed by $S$. aureus, B. subtilis, L. acidophilus, and S. mutans among the Gram-positive bacteria. P. aeruginosa is highly sensitive to the compounds followed by $S$. marcescens, E. faecalis, X. campestris, E. coli, and P. vulgaris among the Gram-negative bacteria. MIC values of B1A B1B, public provident fund and tetracycline against the test bacteria varied from 65 to 100 $\mu \mathrm{g} / \mathrm{ml}, 40-80 \mu \mathrm{g} / \mathrm{ml}, 75-100 \mu \mathrm{g} / \mathrm{ml}$, and $25-50 \mu \mathrm{g} / \mathrm{ml}$, respectively. For fungi, these values ranged from 90 to $100 \mu \mathrm{g} / \mathrm{ml}$ for B1A, $55-75 \mu \mathrm{g} / \mathrm{ml}$ for B1B, $100-125 \mu \mathrm{g} / \mathrm{ml}$ for partially purified fraction, $5-10 \mu \mathrm{g} / \mathrm{ml}$ for carbendazim, and $50 \mu \mathrm{g} / \mathrm{ml}$ for griseofulvin. All the compounds showed good activity against Candida.

\section{REFERENCES}

1. Demain AL, Sanchez S. Microbial drug discovery: 80 years of progress. J Antibiot 2009;62:5-16.

2. de Lima Procópio RE, Da Silva IR, Martins MK, De Azevedo JL, De Araújo JM. Antibiotics produced by Streptomyces. Braz J Infect Dis 2012; $16: 466-71$

3. Levy SB, Marshall B. Antibacterial resistance worldwide: Causes, challenges andresponses. Nat Med 2004;10:122-9.

4. Nathwani D. Tigecycline: Clinical evidence and formulary positioning. Int J Antimicrob Agents 2005;25:185-92.

5. Alanis AJ. Resistance to antibiotics: Are we in the post-antibiotic era? Arch Med Res 2005;36:697-705.

6. Livermore DM. Bacterial resistance: origins, epidemiology and impact. Clin Infect Dis 2003;36:11-23

7. Miyadoh S. Research on antibiotic screening in Japan over the last decade: A producing microorganisms approach. Actinomycetologica 1993;9:100-6.

8. Munaganti RK, Naragani K, Muvva V. Antimicrobial profile of Rhodococcus erythropolis VL-RK_05 isolated from Mango Orchards. Int J Pharm Sci Res 2015;6:1805-12.

9. Srinivasan MC, Laxman RS, Deshpande MV. Physiology and nutritional aspects of actinomycetes: An overview. World J Microbiol Biotechnol 1991;7:171-84

10. Saurav K, Kannabiran K. Diversity and optimization of process parameters for the growth of Streptomyces VITSVK 9 sp. Isolation from Bay of Bengal. India J Nat Environ Sci 2010;1:56-65.

11. Elliah P, Srinivasulu B, Adinarayana K. Optimization studies on neomycin production by a mutant strain of Streptomyces marinensis in solid state fermentation process. Biochemistry 2000;39:529-34.

12. Kathiresan K, Balagurunathan R, Selvam MM. Fungicidal activity of marine actinomycetes against phytopathogenic fungi. Ind $\mathrm{J}$ Biotechnol 2005;4:271-6.

13. Farid MA, El-Enshasy HE, Ei-Diwany AI, El-sayed EA. Optimization of the cultivation medium for Natamycin production by Streptomyces netalensis. J Basic Microbiol 2000;40:157-66.

14. Konda S, Raparthi S, Bhaskar K, Munaganti RK, Guguloth V, Nagarapu L, et al. Synthesis and antimicrobial activity of novel benzoxazine sulfonamide derivatives. Bioorg Med Chem Lett 2015;25:1643-6.

15. Naragani K, Mangamuri U, Muvva V, Poda S, Munaganti RK. Antimicrobial potential of Streptomyces cheonanensis VUK-A from mangrove origin. Int J Pharm Pharm Sci 2016;8:53-7.

16. Boussada O, Ammar A, Saidana D, Chriaa J, Chraif I, Dami M, et al. Chemical composition and antimicrobial activity of volatile components from capituila and aerial parts of Rhaponticum acaule DC growing wildin Tunisia. Microbial Res 2008;163:87-95

17. Bindhu BS, Muvva VL, Munaganti RK, Naragani K, Konda S, Dorigondla KR. A study on production of antimicrobial metabolites by Streptomyces lavendulocolor VHB-9 isolated from Granite soils. Braz Arch Biol Technol 2016;60:1-13.

18. Munaganti RK, Muvva VL, Konda S, Naragani K, Mangamuri UK, Dorigandla KR, et al. Antimicrobial profile of Arthrobacter kerguelensis VL-RK 09. Braz J Microbiol 2016;47:1030-8.

19. Otani T, Yamawaki Y, Matsumoto H, Minami Y, Yamada Y, Marunaka T, et al. New antibiotics. 4181-A and B from Streptomyces griseus: Taxonomy, fermentation, isolation and characterization. J Antibiot
1988;3:275-81.

20. Sujatha P, Bapiraju KV, Ramana T. Studies on a new marine streptomycete BT-408 producing polyketide antibiotic SBR-22 effective against methicillin resistant Staphylococcus aureus. Microbiol Res 2005;160:119-26.

21. Kavitha A, Vijayalakshmi M. Production of amylases by Streptomyces tendae TK-VL 333. Int J Cur Res 2010;10:110-4

22. Kavitha A, Vijayalakshmi M. Cultural parameters affecting the production of bioactive metabolites by Nocardia levis MK-VL-113. J Appl Sci Res 2009;5:2138-47.

23. Anupama M, Narayana KJ, Vijayalakshmi M. Screening of Streptomyces purpeofuscus for antimicrobial metabolites. Res J Microbiol 2007;4:1-3.

24. Narayana KJP, Vijayalakshmi M. Production of extracelluar $\alpha$-amylase by Streptomyces albidoflavus. Asian J Biochem 2008;3:194-7.

25. Harindran J, Gupte TE, Naik SR. HA-1-92, a new antifungal antibiotic produced by Streptomyces CDRIL-312: Fermentation, isolation, purification and biological activity. World J Microbiol Biotechnol 1999; $15: 425-30$

26. Parag SS, Rekha SS. Optimization of nutrional requirements and feeding strategies for Clavulanic acid production by Streptomyces clavuligerus. Biores Technol 2007:98:2010-7.

27. Thakur D, Bora TC, Bordoloi GN, Mazumdar S. Influence of nutrition andculturing conditions for optimum growth and antimicrobial metabolite production by Streptomyces sp. 201. J Med Mycol 2009;19:161-7.

28. Battacharyya BK, Pal SC, Sen SK. Antibiotic production by Streptomyces hygroscopicus. D1.5: Cultural effect. Rev Microbiol $1998 ; 29: 49-52$

29. Atta HM, Bayoumi R, El-Sehrawi M, Aboshady A, Al-Huminay A. Biotechnological application for producing some antimicrobial agents byactinomycetes isolates from Al-Khurmah governorate. Eur J Appl Sci 2010;2:98-107.

30. Kumar S, Krishnan K. Bioactivity guided extraction of 5-(2,4-dimethylbenzyl)pyrrolidin-2-one from marine Streptomyces VITSVK5 spp. and its anti- Aspergillus activity against drug resistant clinical isolates. Pharm Lett 2013;5:178-84

31. Indupalli MD, Vijayalakshmi M, Kumar MR. Streptomyces cellulosae VJDS-1, a promising source for potential bioactive compounds. Int J Pharm Pharm Sci 2015;7:57-61.

32. Naragani K, Kumar MR, Kiranmayi MU, Vijayalakshmi M. Optimization of culture conditions for enhanced antimicrobial activity of Rhodococcus erythropolisVLK-12 isolated from South Coast of Andhra Pradesh, India. Brit Microbiol Res J 2014;4:63-79.

33. Gesheva V, Ivanova V, Gesheva R. Effect of nutrients on the production of AK-111-81 macrolide antibiotic by Streptomyces hygroscopicus. Microbiol Res 2005; 160:243-8.

34. Konstantinovic SS, Veljkovic VB, Savic DS, et al. The impact of different carbon and nitrogen sources on antibiotic production by Streptomyces hygroscopicus CH-7. Cur Res Tech Edu Top Appl Microbiol Microb Biotechn 2010;2:1337-42.

35. Chattopadhyay D, Sen SK. Optimization of cultural conditions for antifungal antibiotic accumulation by Streptomyces rochei G164. Hindustan. Antibiot Bull 1997;39:64-71.

36. Han WC, Lee JY, Park DH, Lim CK, Hwang BK. Isolation and antifungal and antioomycete activity of Streptomyces scabie strain PK-a41, the causal agent of common scab disease. Plant Pathol J 2004;20:115-26.

37. Kannan RR, Iniyan AM, Vincent SG. Production of a compound against methicillin resistant Staphylococcus aureus (MRSA) from Streptomyces rubrolavendulae ICN3 and its evaluation in zebrafish embryos. Indian J Med Res 2014;139:913-20.

38. Ripa FA, Nikkon F, Zaman S, Khondkar P. Optimal conditions for antimicrobial metabolites production from a new Streptomyces sp. RUPA-08PR isolated from Bangladeshi soil. Microbiology 2009;37:211-4

39. Kiranmayi MU, Sudhakar P, Vijayalakshmi M. Production and optimization of L-asparaginase by an actinobacterium isolated from Nizampatnam mangrove ecosystem. J Environ Biol 2014;35:799-805. 